\title{
A DESISTÊNCIA ESCOLAR NOS CURSOS DE GRADUAÇÃO EM ENSINO A DISTÂNCIA - UM PROBLEMA COM CARACTERÍSTICAS BRASILEIRAS
}

\author{
SÃO PAULO/SP MAIO/2018
}

\author{
ITALO FRANCISCO CURCIO - UPM - curcio@mackenzie.br
}

Tipo: Relato de Experiência Inovadora (EI)

Categoria: Gerenciamento e Logística

Setor Educacional: EDUCAÇÃO SUPERIOR, EDUCAÇÃO CONTINUADA EM GERAL

\begin{abstract}
RESUMO
A criação e o desenvolvimento de qualquer curso requer de seu gestor uma série de ações prévias, que nem sempre são observadas com o necessário rigor. Além de sua natureza, quanto ao nível, se é de Educação Básica, Técnico Profissionalizante, Educação Superior, Graduação, Extensão Universitária ou Pós-Graduação, ou à área à qual pertence, deve-se conhecer bem o público alvo a ser atingido, seu grau de receptividade ao curso e características gerais, que delineiam seu perfil e que podem apontar previamente, com razoável segurança, o índice dos possíveis concluintes, comparado ao número de ingressantes. No universo constituído pelas instituições pesquisadas no presente trabalho foi percebida a preocupação dos gestores e demais responsáveis, quanto às metodologias e estratégias, corpo docente, acervo bibliográfico e de laboratórios, dentre outras necessidades materiais e humanas, porém, não foi percebida a preocupação de se conhecer o perfil do ingressante, com suas diversas características específicas, que podem ser obtidas mediante informações fornecidas por ele mesmo, por meio de uma avaliação diagnóstica aplicada antes do início do curso, e que deverão ser ratificadas ou não, no máximo em até um mês, após seu ingresso. Estas informações devidamente tabuladas, conforme proposta do presente trabalho, nortearão a conduta do gestor, durante 0 transcorrer do curso. Como objeto final, obteve-se um algoritmo, que poderá dar a probabilidade de $o$ aluno ser ou não um possível desistente. Tal algoritmo é obtido a partir da comparação das características do ingressante, obtidas por meio da referida avaliação diagnóstica, e as dos desistentes. Destaca-se também, que, embora o universo da pesquisa se refira a cursos oferecidos na modalidade a distância, o algoritmo obtido tem caráter universal, bem como o processo desenvolvido para sua obtenção, por isso, é aplicável para qualquer nível de curso, oferecido tanto na modalidade a distância, quanto presencial ou "hibrido".
\end{abstract}

Palavras-chave: Ensino a Distância; Gestão Escolar; Perfil de Aluno; Desistência Escolar; Algoritmo.

\section{AGRADECIMENTOS}

À UNIVERSIDADE PRESBITERIANA MACKENZIE (UPM), SP - BRASIL, E À UNIVERSIDADE DO MINHO - PORTUGAL, PELO APOIO LOGÍSTICO DA PESQUISA, E AO MACKPESQUISA, ÓRGÃO INSTITUCIONAL DA UPM DE FOMENTO À PESQUISA. 


\section{Introdução}

Ao se iniciar qualquer pesquisa científica, seu autor ou autores, certamente, se nortearão pelo Método, que embora não seja uma proposta atual, também não é tão antiga, ao se comparar com o tempo de existência da humanidade na Terra ou mesmo de certas culturas milenares, que subsistem até hoje.

O Método Científico, apresentado a partir do século XVII, da atual era, resultou num novo conceito da palavra Ciência, que até então se concebia simplesmente como sinônimo de saber.

A partir deste conceito, os chamados pesquisadores passaram a dialogar com a Natureza e seus integrantes, com linguagens, que, embora fossem conhecidas pelas diferentes culturas, não eram utilizadas propriamente como nos moldes atuais, mas, na maioria das vezes, como instrumento ou ferramenta, numa concepção mais técnica.

Talvez, dentre essas linguagens, a Matemática foi a mais emblemática, pois, de uma ferramenta, para o atendimento de necessidades do homem, passou a ser o meio de comunicação entre o pesquisador e a Natureza.

Nas palavras de Galileo Galilei: "A Matemática é o alfabeto com o qual Deus escreveu o Universo".

Não obstante uma metáfora, tal expressão tem significado profundo, pois diferentes fenômenos conhecidos atualmente pelo homem, tanto no âmbito específico da humanidade, ou da Natureza em geral, são estudados com base em modelos matemáticos, ou leis matemáticas.

Todavia, não só a Matemática passou a ser a linguagem para o diálogo entre o homem e a Natureza, mas outras também, como a Música, a Imagética e as próprias Línguas conhecidas, acrescidas das que surgiriam posteriormente, como o caso da Língua de Sinais e o "Braile".

Com estas linguagens, o ser humano, interessado no estudo dele próprio e da Natureza como um todo, passou a investigar fenômenos com especificidades, que resultaram nas diferentes Ciências conhecidas hoje, que compuseram dois grandes grupos: o das Ciências Humanas (ou Humanidades) e o das Ciências da Natureza (ou Ciências Naturais). 
Paralelamente, a Matemática permaneceu como Linguagem e, com ela, diversos estudos, até poucos séculos atrás sequer imaginados, passaram a ser feitos, e resultaram no surgimento de outras ciências.

Dentre os diferentes ramos da Matemática, um que se destacou foi a Estatística, com o uso da qual se desenvolveram várias pesquisas científicas, que proporcionaram soluções de problemas, tidos em princípio como de difícil superação.

Segundo Stigler (2000), embora a Estatística tenha suas origens citadas desde a Antiguidade, foi a partir do século XVII que passou a ter grande aplicação, e mais ainda na segunda metade do século XIX, associada aos diversos problemas das Ciências Naturais e das Ciências Sociais.

Com a Estatística, por exemplo, permitiu-se desenvolver, inclusive, mecanismos que possibilitam não só a previsão de problemas, como inclusive sua prevenção. Sobretudo nas ciências ligadas diretamente ao comportamento do homem, físico ou social, seu grande avanço no último século se deveu muito aos cálculos de probabilidade e tratamento estatístico, que embasaram novos modelos, não só para a solução de problemas, mas, também de prevenção.

A Medicina Clínica, de caráter preventivo, dentre outras áreas do conhecimento, é uma das grandes beneficiárias da Estatística, assim como as Ciências Políticas e as Ciências Econômicas.

No âmbito da Educação, porém, existem poucos trabalhos desta natureza e isto faz com que as ações desenvolvidas por professores e gestores se baseiem geralmente em dados de fatos consumados e não de fatos previsíveis.

Lourenço Filho (1974), há quase cem anos, falava acerca da importância e da necessidade de se conhecer novos sistemas didáticos, mencionando contribuições de Maria Montessori (1870 - 1952) e de Jean-Ovide Decroly (1871 - 1932).

Depois dele, vieram outros, também com propostas interessantes e que proporcionaram grandes saltos na forma de pensar e de agir, não apenas no Ensino, mas, principalmente, na Educação, como Paulo Freire (1921 - 1997), Edgard Morin (1921), Emília Ferrero (1936), e mais recentemente, Antônio Nóvoa (1954) e Philippe Perrenoud (1959).

No entanto, percebe-se que todos estes pensadores, e mais alguns que poderiam ser 
citados, se ativeram e se atêm muito mais à Epistemologia da Educação, deixando poucos registros significativos, que sugiram diretamente a utilização de recursos de gestão, comuns em diversas áreas da sociedade, bem como o uso de novas tecnologias, disponíveis para múltiplas ações. Seus trabalhos referem-se ainda a modelos clássicos de instituições, que têm como protagonista apenas o professor, detentor do conhecimento e responsável pelo Ensino e Educação.

Este comportamento ainda é pautado pelo respeito a uma linha de conduta que tem mais de um século e meio.

Na primeira metade do século XIX, Bonald (1853) falava do protagonismo do professor e do "bom" uso da linguagem, ou de novas linguagens, devido à sua importância e de sua necessidade para que o homem viva em sociedade. Todavia, este conceito era restrito à sua época, pois a linguagem, ou linguagens às quais se referia decorriam de sua língua pátria. As linguagens mencionadas anteriormente não eram ainda assimiladas como 0 são hoje. Atualmente, independentemente de sua formação cultural, mesmo o cidadão comum lida com diversas linguagens, além das decorrentes de sua língua pátria, pois são várias as instituições que participam de sua formação e não somente as seculares, como a Escola, Igreja e Família.

Conta-se hoje também com as diversas mídias, de poder de alcance incomensurável. E, não obstante a carga tradicional que o vocábulo ainda possui, a figura do professor passou a ter uma conotação muito mais abrangente, indo além de um atributo singular, como se preconizou durante muito tempo. O professor moderno, numa Escola Moderna, deve apresentar uma versatilidade em estratégias de ensino e um conhecimento multidisciplinar muito além do exigido no passado. O professor é acima de tudo um gestor do conhecimento junto aos seus alunos.

Além disto, existe a figura do Gestor Escolar, no âmbito administrativo da Instituição, o qual, por sua vez, além de ser um professor de larga experiência, deve conhecer bem as Ciências Sociais, ter familiaridade com o cálculo de Probabilidade e Estatística e demonstrar caráter inovador, uma vez que um de seus maiores problemas está nos índices de evasão escolar, que neste trabalho se denomina Desistência Escolar, por questões de conceito.

\section{Objetivos}

O presente trabalho refere-se ao relato de uma experiência inovadora, cujo objeto de estudo abordado é o elevado índice de desistência escolar verificado no Brasil, 
principalmente na Educação Superior, tanto por alunos de cursos oferecidos na modalidade presencial, quanto a distância.

Esta experiência foi vivenciada depois dos resultados obtidos com uma pesquisa de natureza exploratória-explicativa-descritiva, desenvolvida especificamente para o presente trabalho, que mostrou índices ainda maiores, quando o universo investigado envolve cursos oferecidos na modalidade a distância, popularmente conhecidos por cursos em EaD.

Diante do exposto, mostra-se que este caso é na realidade um problema, que para ser resolvido deve ser tratado cientificamente. Sua solução é conseguida com o resultado de pesquisa, que apesar de propor o uso de mecanismos de natureza técnica, sua obtenção procede de conduta científica.

É neste ponto que o presente trabalho se fixou, ou seja, seu objetivo foi o de criar um mecanismo versátil, de caráter científico e testado previamente, que proporcione ao corpo discente dos cursos oferecidos na modalidade a distância um tratamento preventivo, para se evitar a desistência. Tratamento este, semelhante ao empregado pela Medicina Clínica, que é o de se prevenir com relação a certa doença ou de seu agravamento, evitando-se chegar ao óbito.

Por meio da determinação de um algoritmo, cuja utilização permite saber previamente a probabilidade que certo aluno tem, ao ingressar num curso, de ser um potencial desistente, e mediante o conhecimento das eventuais causas que o levariam a esta decisão, é possível diminuir os índices de desistência nesta modalidade de oferta de cursos.

\section{Referencial teórico}

O trabalho aqui apresentado, destaca um tema complexo, que passou a se configurar como problema, em face de inquietações e preocupações de alunos, professores e gestores de cursos de nível superior oferecidos na modalidade a distância: a popularmente denominada "evasão" escolar.

Dados obtidos em órgãos oficiais e em associações idôneas, de Instituições de Ensino do Brasil, mostram que os índices de alunos matriculados em cursos oferecidos na modalidade a distância, e que não os concluem, é da ordem de $80 \%$, em relação ao número de ingressantes. 
Por questões de semântica, trocou-se a palavra evasão pela palavra desistência, pelas razões que serão expostas mais adiante. O verbo evadir, no tema aqui abordado não traduz efetivamente o objeto de investigação, julgando-se assim adequado o verbo desistir.

Em função do pouco número de trabalhos pormenorizados, conhecidos, que tratam deste assunto, este, aqui apresentado é inovador.

O resultado obtido tem caráter universal, e poderá ser de grande utilidade à comunidade acadêmica, sobretudo, para a parcela envolvida com cursos oferecidos na modalidade a distância. Tal resultado, se fundamenta em documentos disponibilizados por instituições idôneas, no âmbito da Educação, teorias consolidadas, registradas na literatura, e pesquisa de campo, de natureza exploratória.

Propositalmente, evitou-se aqui a utilização das expressões Educação a Distância e Ensino a Distância, tendo em vista a ambiguidade existente. Ambiguidade esta que não está na modalidade da oferta, mas no objeto da oferta, portanto entre Educação e Ensino.

Todavia, vale ressaltar que, não obstante a distinção, existe uma relação entre tais conceitos. Para a Educação é imprescindível o Ensino e o Ensino, por sua vez, implica em Educação.

Quando se pensa em oferecer um curso de nível superior à determinada população, diversas decisões são tomadas previamente, dentre as quais, a de o curso ser acadêmico para a prática da docência e (ou) para a pesquisa científica, ou seja, se é de licenciatura ou de bacharelado; ou se será de natureza técnica, com vistas a uma profissionalização fora do universo escolar. Além disto, é também de grande importância a decisão pela modalidade de oferta, se será Presencial, Semipresencial ou a Distância, bem como se a ênfase está apenas no Ensino ou também na Educação.

Esta última menção, embora possa parecer irrelevante, no presente trabalho reveste-se de grande importância, pois, de acordo com a decisão tomada pelos responsáveis do curso, deverá ser feita a análise das possíveis causas que levam o aluno à desistência.

Além destas três decisões prévias, porém, existem outras, dentre as quais o cuidado com a designação dos responsáveis pelo curso. Considerou-se nesta experiência, ser também importante a qualificação profissional, no âmbito das competências dos proponentes, gestores e professores destes cursos. 
Se ocorrer uma imprecisão ou erro nessas decisões iniciais, parte-se para o empirismo e a imprevisibilidade poderá implicar no insucesso, correndo-se o risco, portanto, de se ter um curso praticamente "natimorto".

Por isso, reitera-se neste momento que o problema deve ser tratado cientificamente e não tecnicamente.

Deve-se pensar que os cursos oferecidos pelas Universidades são para atender às necessidades da comunidade, com a formação de profissionais competentes e atualizados, perante a realidade vivenciada pela sociedade no momento. Nesse sentido, reforça-se que, para se lograr o êxito desejado, no contexto da desistência escolar, com o objetivo de reduzí-la ao menor índice possível, o corpo docente, bem como os gestores, principalmente no âmbito pedagógico, devem ser preparados especificamente para sua função.

Bireaud (1995), há mais de duas décadas, destacou a importância da qualificação pedagógica prévia do docente do Ensino e da Educação Superior. Sua obra original, em francês, datada de 1990, destaca o problema quase universal, do despreparo de gestores e docentes, sobretudo os principiantes, para ensinar nas Universidades, e que se deveria pensar seriamente a respeito, em função da rápida evolução do corpo discente que chega nos cursos superiores. Mesmo depois de todo este tempo, o problema é praticamente o mesmo, como mostra Membiela (2015).

$\mathrm{Na}$ época citada por Bireaud (1995), o problema estava restrito aos cursos presenciais, no entanto, decorridos quase trinta anos, com o avanço na oferta de cursos a distância, o problema estendeu-se para esta outra modalidade.

\section{Procedimentos metodológicos}

A hipótese levantada na pesquisa foi a de que a não conclusão de um curso superior oferecido na modalidade a distância, por alunos nele matriculados, não está somente nas características destes alunos, mas envolve o sistema todo: aluno, professor e gestor.

A implantação de um setor na universidade, que oferece cursos na modalidade a distância, apresenta um custo-benefício específico, diferente do setor que se ocupa com cursos oferecidos na modalidade presencial ou semipresencial.

Peculiaridades próprias, inerentes aos cursos na modalidade $\mathrm{EaD}$, ou E-learning, como 
são conhecidos popularmente, requerem investimentos, cujos resultados devem justificálos.

Deste modo, reitera-se que deve-se evitar o empirismo, não obstante o inevitável risco que existe em qualquer empreendimento.

Em função desta concepção, considerou-se importante saber previamente qual é a probabilidade de um ingressante concluir ou não o curso por ele escolhido. Por isso, nesse contexto, apresenta-se o resultado obtido no presente trabalho, que é um algoritmo, de caráter universal, composto a partir de diversas variáveis adotadas previamente.

A decisão por estas variáveis, que comporão o algoritmo, dependerá do universo estatístico contextualizado, delimitado conforme os interesses e necessidades do gestor que o utilizará, bem como seus respectivos fatores de ponderação, denominados pesos.

Daí a importância do cuidado da escolha dessas variáveis, por parte do gestor que fará uso desta "ferramenta".

\section{Apresentação e discussão dos resultados}

O processo deve ser iniciado por uma avaliação diagnóstica aplicada ao ingressante, antes de se começar a frequentar o curso, o qual deverá ser reaplicado entre a segunda e a quarta semana seguintes, com os mesmos itens de consulta. Tal procedimento se justifica para se ter com maior precisão as informações desejadas, que serão necessárias para o desenvolvimento do algoritmo.

A Avaliação Diagnóstica não tem utilidade apenas em sala de aula, ela é também de grande importância no contexto da gestão escolar, para a elaboração do Projeto Pedagógico de um curso ou dos Planos de Ensino de seus componentes curriculares.

Esta Avaliação Diagnóstica aplicada no início do curso proporciona subsídios para a percepção das características mais relevantes e das menos relevantes relativas ao ingressante, que constituirão um banco de informações que alimentará o algoritmo proposto neste trabalho, cujo objetivo, como já se mencionou, é dar ao gestor a probabilidade de um ingressante de um curso oferecido com $\mathrm{EaD}$, por certa Universidade, ser também um concluinte. Com este algoritmo e os dados que possui, para sua elaboração, o gestor deste curso tem condições de agir paralelamente durante seu desenvolvimento, superar problemas e, muitas vezes, até evitá-los. 
A elaboração deste algoritmo se deu após a aplicação de uma Avaliação Diagnóstica aos ingressantes, a partir da qual se estabeleceram as variáveis de entrada. O modelo proposto foi dividido em três partes:

I. Instrumento com informações referentes aos pré-requisitos considerados relevantes para se ter proveitoso acompanhamento dos conteúdos programáticos dos respectivos componentes e (ou) disciplinas que constituem a Matriz Curricular do curso;

II.Instrumento com informações do candidato ou do ingressante, referentes às suas aptidões, expectativas e justificativas pela escolha do curso;

III.Instrumento com informações concernentes ao perfil do aluno, em nível profissional e social, que permite estabelecer as variáveis de entrada, para a obtenção do algoritmo.

Com base nas orientações de Guimarães \& Lages (2008), a tabulação de dados foi feita de forma simples, por meio de tabelas convencionais, de fácil leitura para a obtenção de informações. Após o tratamento estatístico desses dados chegou-se ao modelo matemático seguinte, de caráter universal, que é equação base do algoritmo, que fornece a referida probabilidade:

\section{Considerações finais}

Diferentemente de outras atividades desenvolvidas pelo homem, sobretudo as que se referem às tecnologias ligadas ao concreto, como produção e manutenção de máquinas e equipamentos, agricultura, construção civil, indústria do mobiliário, roupas, dentre outras, o Ensino e a Educação estão intimamente ligadas à percepção e aos sentimentos humanos.

Não se está a dizer, contudo, que as demais atividades mencionadas prescindam da percepção e dos sentimentos humanos, pois seria negar a própria interação do homem com a Natureza, mas, quando se fala de Ensino e de Educação, as singularidades, sejam do aluno, quanto do professor e do gestor escolar, são recorrentes e corriqueiras.

Um mesmo professor, quando dispensa sua atenção a dois alunos distintos, mesmo que sejam de uma mesma turma, com a mesma disciplina e conteúdo, o faz de maneira distinta e singular, pois, percebe e sente que o poder de assimilação de cada um é diferente.

Merleau-Ponty (2006), deixa claro que percepção e sensação, num ser humano, estão 
juntas, por isso, o professor se manifesta de maneira distinta com relação a cada um destes dois alunos. Daí, alguns chegam a atribuir isto ao feelingdo professor.

É neste sentido, que a experiência relatada no presente trabalho se torna importante neste momento, pois após obter os resultados da avaliação diagnóstica, o professor e o gestor de um curso, além de todo seu embasamento teórico e conhecimento específico da estrutura educacional, da qual é parte integrante, deve manifestar seu feeling, planejar e desenvolver ações, para lograr o êxito esperado.

Como na Medicina Clínica Preventiva, na qual se trabalha mediante informações que constituem um diagnóstico, a partir dos resultados obtidos com o uso deste algoritmo, 0 gestor do curso pode agir previamente e preventivamente, e assim evitar ou então atenuar efeitos dos problemas, quando os mesmos não puderam ser evitados, e já ocorreram.

\section{Referências}

BIREAUD, Annnie. Os métodos Pedagógicos no Ensino Superior. Porto: Porto Editora, 1995.

BONALD, M. de. Recherches philosophiques. Sur les premiers objets des connaissances morales.Paris: d'Adrien Le Clere, 1853.

GUIMARÃES, Ângelo de M. \& LAGES, Newton A. C. Algoritmos e Estruturas de Dados. Rio de Janeiro: LTC, 2008.

LOURENÇO FILHO, Manuel Bergström. Introdução ao estudo da Escola Nova.11. ed. Melhoramentos. São Paulo: 1974.

MEMBIELA, Pedro (org.). Nuevos Encenários en la docencia universitaria.Vigo: Educación Editora, 2015.

MERLEAU-PONTY, Maurice. Fenomenologia da percepção. São Paulo: Martins Fontes, 2006

STIGLER, Stephen M. The History of Statistics - The Measurement of Uncertainty before 1900. Cambridge: Belknap Press, 2000. 